\title{
Roberto Alcázar y Pedrín como paradigma sociológico del periodo de la autarquía en España (1939-1959)
}

\author{
LucAs E. LORDuY
}

Graduado en Historia del Arte (Universidad de Valencia). Máster EEES en Métodos y técnicas avanzadas de investigación histórica, artística y geográfica (UNED).

Fecha de recepción: 6 de octubre de 2016

Fecha de aceptación definitiva: 9 de noviembre de 2016 


\title{
Resumen
}

Roberto Alcázar y Pedrín es una serie de cómic publicada en España (1941-1976), en la que sus protagonistas mantienen una lucha constante contra el mal, encarnado en bandas de delincuentes, científicos locos y villanos. En este ensayo trataremos de vislumbrar cómo este cómic reflejaría la sociedad en el periodo de la autarquía franquista (1939-1959). Con este fin se estudian las características de los personajes, su contextualización, la imagen y los contenidos de la narración. Se pone de manifiesto cómo este medio mostraría la ideología del régimen y cómo afectaría a una clase popular con niveles bajos de educación.

Palabras clave: autarquía, aventura, franquismo, Roberto Alcázar, Pedrín, cómic

\begin{abstract}
Roberto Alcázar y Pedrin is a comic series published in Spain (1941-1976), in which the main characters maintain a constant struggle against evil incarnated in gangsters, mad scientists and villains. In this essay we will try to glimpse how this comic reflects society in the period of Franco autarchy (1939-1959). For this purpose the characters in the comic, their contextualization, the image and the contents of the narrative are studied. It shows how this medium would show the regime's ideology and how it would affect a popular class with low levels of education.
\end{abstract}

Keywords: autarchy, adventure, francoism, Roberto Alcázar, Pedrín, comic

\section{Cita bibliográfica}

Lorduy Osés, L. E. «Roberto Alcázar y Pedrín como paradigma sociológico del periodo de la autarquía en España (1939-1959)», en CuCo, Cuadernos de cómic, n. 7 (2016), pp. 66-86. 
La utilización del cómic en su condición de medio de expresión artística como fuente para el estudio de la historia contemporánea ha sido posible, ya entrado el siglo xx, a partir del desarrollo formal y consolidación de este género entre el gran público. En este contexto, el cómic ha sido aplicado al estudio de momentos históricos característicos a partir de sus contenidos como reflejo, si no de manera evidente, sí significativa, de esa misma realidad histórica. Es el caso de buena parte de las historietas españolas producidas durante el franquismo.

Entre ellas, el ejemplo concreto que utilizaremos, Roberto Alcázar y Pedrín -Editorial Valenciana S. A.- , sería una de las series españolas de cuadernos de aventuras ${ }^{1}$ que cumpliría esos requisitos para el ensayo que abordamos.

Creada esta serie en el año 1941 por el editor Juan Bautista Puerto, que ejercería inicialmente como guionista junto al dibujante Eduardo Vañó, se constituiría con una periodicidad aproximadamente semanal, ${ }^{2}$ perdurando hasta 1976, publicándose 1219 números además de otros extraordinarios. Se considera, como otros cuadernos de aventuras, heredera de los relatos folletinescos ${ }^{3}$ en lo concerniente a la continuidad de unos personajes fijos entre episodios diferentes, así como de ciertos tópicos y esquemas, además de por ser narraciones basadas en estereotipos — con los que se juega — que los lectores ya conocen, introduciendo algún elemento nuevo. ${ }^{4}$

${ }^{1}$ Se trataría de una de las primeras series en España de lo que se conocerá como cuaderno de aventuras: entre diez y quince páginas, papel de baja calidad, impresión en blanco y negro, formato apaisado de 24 x $17 \mathrm{~cm}$., grapados en el lomo, y fundamentalmente destinadoa al recreo, la evasión y la diversión de jóvenes y clases populares; en definitiva, un público amplio y poco exigente.

${ }^{2}$ Hasta el año 1952, estaba prohibida la periodicidad como tal de este tipo de publicaciones, y el permiso de edición se gestionaba por el editor ejemplar a ejemplar en cada colección, como «folleto no periódico», constituyendo series consecutivas que de hecho podían ser aproximadamente semanales. Porcel, P. «La historieta española de 1951 a 1970», en Arbor, n. ${ }^{\circ}$ extraordinario (septiembre 2011), p. 130.

${ }^{3}$ Los folletines — relatos de ficción por entregas, de tipo melodramático y pasional— se han considerado como un subgénero literario del siglo xix en tanto producto destinado al sector obrero dentro del proceso de mercantilización literaria, en los que se enfrentaban la maldad de los patronos y la bondad de los obreros, y el triunfo de la justicia y el amor, todo ello como elemento compensador o consolador, mediante proyección e identificación de sus receptores - las clases bajas - con los personajes presentados. Véase, VV. AA. «El folletín por entregas y el serial», en Anàlisi, n. o 9 (1984), pp. 143-166. Disponible en http://www.raco.cat/index. $\mathrm{php} /$ Analisi/article/view/41273/88288

${ }^{4}$ Gual Boronat, Ó. Viñetas de posguerra. Los cómics como fuente para el estudio de la historia. Valencia, Universitat de València, 2013, 68-71. 
Sus creadores eran emprendedores procedentes de la clase trabajadora que se dedicaron de manera semiindustrial, y con escasos conocimientos técnicos, a la elaboración de estos cuadernos de acción basados en los tópicos de la cultura popular del momento. Esta serie de historietas - poco documentadas, con escasa ambientación y muy sintéticas en su argumento por su breve extensión- está protagonizada por un héroe, el periodista-detective Roberto Alcázar, que junto a su inseparable compañero adolescente, Pedrín, en coincidencia con el patrón establecido por la serie estadounidense Batman, ${ }^{5}$ mantiene una lucha constante contra el mal, encarnado en bandas de delincuentes, científicos locos, villanos de distinto pelaje o incluso monstruos del tipo de las películas americanas de la Universal (FIG. 1).

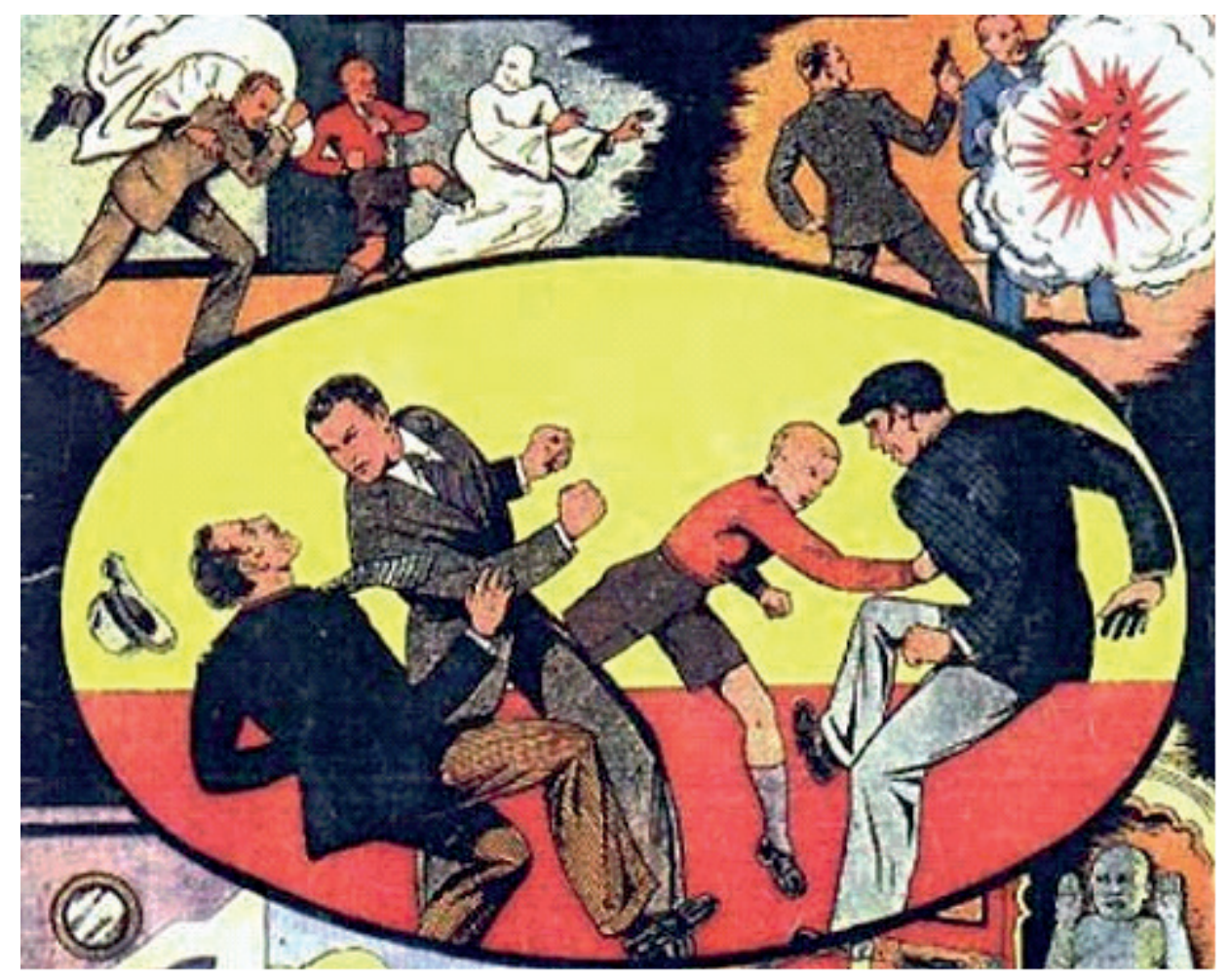

FIG. 1. Roberto Alcázar y Pedrín. Editorial Valenciana S.A., 1944. Detalle de la portada del almanaque. Esta imagen y siguientes son obra de Eduardo Vañó y guionistas no acreditados.

Estos cuadernos de aventuras eran, sin embargo, productos eminentemente autóctonos que ponían de manifiesto de manera implícita cómo era la sociedad y el modo de pensar bajo el régimen franquista en sus diversas etapas.

La posguerra aparece como un tiempo nuevo en el que todo atisbo del pasado republicano ha dejado de existir. El régimen que se había instaurado tras la guerra necesitaba controlar

\footnotetext{
${ }^{5}$ El patrón de Batman y Robin. La serie fue creada en Estados Unidos en 1939 por Bob Kane y Bill Finger, a partir del episodio n. 27 de la revista Detective Comics de la editorial National Publications.
} 
muchos aspectos de la vida para poder restablecer un nuevo orden a su medida. Uno de los canales que utilizó el franquismo para este fin fue el desarrollo de una retórica populista, donde su imagen pública, la que quería proyectar de sí mismo, se extendería a través de la prensa y de otros productos impresos populares, como las historietas entre otros. ${ }^{6}$ Así, el gobierno utilizaría ya tempranamente la prensa infantil como medio de una penetración ideológica. ${ }^{7}$ Como consecuencia de ello, las historietas se llenaron de consignas, subordinándose la imagen al texto, ya que era conocido que muchas de las historietas no solo las leían los niños, sino que su difusión se centraba especialmente entre jóvenes y adultos de distintas capas sociales y geografías diferentes, que sin una cultura académica y sin hábitos de lectura, tónica general en la sociedad de la época, las tenían como pasatiempo lúdico y gratificante, por su lectura fácil, de texto sencillo y comprensible, además de asequible, y que daban lugar a mundos ficticios donde soñar, más allá de la penosa realidad. ${ }^{8}$

A partir de este contexto, ha existido desde la transición una cierta polémica en cuanto a la identificación del producto - la serie Roberto Alcázar y Pedrin - con los tiempos que la vieron nacer, en cuanto a si la serie tenía intención adoctrinadora, si había ultranacionalismo en ella, un afán totalitario, un culto a las jerarquías, o una sumisión del individuo frente a las estructuras del Estado.

Así, Juan Antonio Ramírez otorgaría un cariz político a la serie, por ejemplo, en lo referente a:

La sumisión de los adolescentes [representados por Pedrín] —las nuevas generaciones que no han hecho la guerra - a los ideales del nuevo hombre del régimen [Roberto Alcázar], un poco monje y un poco soldado, de buena posición social, defensor de la ley — la propiedad privada de los estados capitalistas contra espías y conspiraciones de toda laña.

De la misma manera ocurre en lo relativo al individualismo de Roberto Alcázar, que sería «una cualidad estrechamente ligada a las circunstancias particulares de la España autárquica, expulsada de las Naciones Unidas». ${ }^{10}$ Por otra parte, asociaría la semejanza fisionómica

${ }^{6}$ Molinero, C. La captación de las masas. Política social y propaganda en el régimen franquista. Madrid, Cátedra 2005, p. 11 .

7 Con el ejemplo arquetípico de la revista de historietas Flechas y Pelayos, publicada entre los años 1938 y 1949 bajo el patrocinio de FET y de las JONS y la dirección de fray Justo Pérez de Urbel — miembro de la orden benedictina, Consejero Nacional del Movimiento y procurador en Cortes entre 1943 y 1946-, al objeto de dar a los niños «la formación humana, religiosa y patriótica que hará de ellos buenos cristianos y excelentes españoles». Otero, L. Flechas y Pelayos. Moral y estilo de los niños franquistas que soñaban imperios. Madrid, Editorial EDAF, 2000, p. 10.

8 Aparece también el intercambio y el alquiler de historietas que se convirtieron en el refugio del público menos afortunado económicamente. Al préstamo se le sumaba la compraventa de segunda mano, creando un mercado paralelo. Lara, A. (coord.) Tebeos, Los primeros cien años. Madrid, Anaya, 1996, p. 93.

9 Ramírez,J.A. «Grupos temáticos del tebeo de aventura en la España de posguerra: Notas para una historia de la iconografía e ideología (y II)», en Cuadernos de Realidades Sociales, n. 9 (1976), pp. 87-150.

10 Ramírez, J. A. «Estructura e ideología del tebeo de aventuras en la España de la posguerra», en Cuadernos 
de Roberto Alcázar con la de José Antonio Primo de Rivera, considerando a este como el "prototipo del héroe» de la historieta. ${ }^{11}$

Por el contrario, otros teóricos de la novela gráfica y el cómic vienen a negar lo anterior, postulando que Roberto Alcázar y Pedrín quedaría desde su inicio al margen del control ideológico directo y del adoctrinamiento franquista. Así, Pedro Porcel indica:

Lo insuficiente y parcial de una interpretación únicamente política de estas historietas: en absoluto existe en ellas intención adoctrinadora... Frente a la torpe acusación de fascista de que tantas veces ha sido objeto, puede afirmarse con rotundidad que no existe una sola frase en los mil doscientos diecinueve episodios en los que quede patente esta adhesión de los héroes a esta ideología política. ${ }^{12}$

Más cercano a la mentalidad del lector que la mayoría de los héroes norteamericanos, ahíto de referentes de sobra conocidos y dueño de formas y recursos muy primarios, [Roberto Alcázar] se dirige al público español en su propio lenguaje, precario, sencillo y expeditivo, ejemplar fruto de su tiempo. Que no significa, como en otras ocasiones he dicho, que sea en absoluto un héroe fascista ni mucho menos un vehículo de propaganda utilizado por el régimen, por más que semejante infundio haya sido largamente repetido. Confundir lo que no son sino lugares comunes de la narrativa de acción con franquismo es un disparate que no revela más que un profundo desconocimiento de las estructuras del género, además de la pretensión de juzgar una obra prescindiendo alegremente de su contexto. No vale la pena seguir perdiendo el tiempo en una discusión que hace ya tiempo debió cerrarse. Roberto y Pedrín son hijos del folletín y del racionamiento, dilectos y enloquecidos continuadores de una tradición de héroes sencillos y contundentes que los emparenta, gracias a la acogida que el público les dispensa y a su concienzudo repaso al universo folletinesco, con otros paladines del subdesarrollo, como el Santo mexicano, al que nadie en su sano juicio se ha atrevido a calificar de fascista, o con la inmensa mayoría de protagonistas de los seriales, gente de una sola pieza tan amiga de la razón de la fuerza como los dos campeones de la posguerra. ${ }^{13}$

Según el planteamiento de Pedro Porcel, los autores, aunque bajo el foco de la censura — de hecho recoge las observaciones de la ficha de la censura para el n. ${ }^{\circ} 1$ de la serie. Valor literario o artístico: mediano. Otras observaciones: narración a base de dibujos. Argumento fantástico, inverosímil y de mediano o escaso interés. Cosa floja - ${ }^{14}$, se apartarían de cualquier tentación ideológica mediante estrategias como la de no referirse en ningún caso a España - un país supuestamente tranquilo y sin delitos donde no pueden ocurrir hechos como los desarrollados en las historietas-, ubicando la acción, muchas veces violenta, en espacios indeterminados e intemporales donde los protagonistas saltan las fronteras de un episodio a otro, haciéndose partícipes de múltiples tópicos en cuanto a lo oriental y lo occidental, las razas o los personajes presentados. Pero dentro de este entramado, cualquiera de los episodios se mostrará como un reflejo de la sociedad española de su tiempo, de los valores

de Realidades Sociales, n. 13 (1977), p. 27.

11 Ramírez, J. A. (1976), op. cit., p. 104.

12 Porcel, P. La historia del tebeo valenciano. Onil, Edicions de Ponent, 2002, pp. 114-115.

13 Porcel, P. Superhombres ibéricos. Onil, Edicions de Ponent, 2014, pp. 87-88.

${ }^{14}$ Ibid., p. 87. 
y sentimientos imperantes en la clase popular, de donde proceden sus autores, señalándose modas, inquietudes morales o actitudes que se presentaban en la vida cotidiana.

Esta polémica es tratada de manera implícita por Óscar Gual en su tesis doctoral ${ }^{15}$ y en su obra posterior ${ }^{16}$ relativas al tema en cuestión, desarrollándolo ampliamente y poniendo de manifiesto ambas posturas, con un planteamiento netamente académico.

A partir de todo ello, analizaremos esta serie de cuadernos de aventuras mediante una metodología basada en la investigación comparativa de diversos episodios, siendo la contextualización su eje fundamental. El análisis se ha realizado a niveles narrativo e iconográfico en cuanto a contenidos, espacio-temporal en cuanto a su puesta en escena, y respecto a los personajes. Por otra parte, se analiza su ideología implícita o explícita, propia del sistema dominante, la transmisión de valores y modelos de conductas sociales.

Delimitaremos el estudio a un espacio temporal entre el primer número de esta serie, en 1941, hasta lo publicado en 1959 - siempre durante la etapa de autarquía franquista - con el punto de inflexión en 1952, cuando se produce un cambio en el panorama editorial relativo a este tipo de publicaciones, ${ }^{17}$ además de un paulatino cambio sociológico en respuesta al tímido aperturismo que experimenta España en ese tiempo. ${ }^{18}$

\section{Contexto político}

La Ley de Prensa e Imprenta de 1938 suponía el control total de la prensa, que quedaba sujeta al Estado como un servicio público, incluso en el caso de la prensa de propiedad de empresas privadas. Se establecía la censura previa de todas las publicaciones impresas antes de su difusión, los directores serían nombrados por el Ministerio de la Gobernación y tenían que jurar los Principios Fundamentales del Movimiento Nacional y ser militantes de FET y de las JONS.

Los permisos de edición de nuevas publicaciones periódicas se otorgaban solo a organismos oficiales y a empresas - empresarios- que se habían hecho merecedores de ello por los servicios prestados durante la Guerra Civil. Para el caso de publicaciones periódicas

${ }_{15}$ Gual Boronat, Ó. Bocadillos de autarquía. La historieta del primer franquismo. Valencia, Departament d' Historia Contemporània. Universitat de València, 2008.

${ }^{16}$ Gual Boronat, Ó. (2013), op. cit., pp. 67-111.

17 A partir de 1952, el papel y los permisos de edición son más fáciles de conseguir, nacen nuevas editoriales, se lanzan nuevas series de historietas con periodicidad fija, todo ello bajo el nuevo control de la Dirección General de Prensa del Ministerio de Información y Turismo al desaparecer la Vicesecretaría de Educación Popular de FET y de las JONS, anteriormente encargada de supervisar este tipo de publicaciones. VÁzQUEz, J. M. Prensa Infantil y Juvenil: Pasado y presente. Madrid, Comisión de Información y Publicaciones Infantiles y Juveniles. Dirección General de Prensa del Ministerio de Información y Turismo, 1967, p. 28.

18 Entrada en la FAO en 1950, en la UNESCO en 1952, y los acuerdos con la Santa Sede y con los Estados Unidos en 1953. 
infantiles, los procedimientos se dejaban en última instancia en manos de fray Justo Pérez de Urbel - monje benedictino, primer abad del monasterio del Valle de los Caídos, consejero nacional del Movimiento, y procurador en Cortes- que restringió las autorizaciones entre 1939 y 1945 en favor de la revista Flechas y Pelayos y unas pocas más, como Chicos, controlada por Consuelo Gil Roësset. ${ }^{19}$ Las restantes publicaciones eran consideradas no periódicas - publicaciones unitarias y folletos- que debían renovar el permiso de edición número a número, como es el caso de Roberto Alcázar y Pedrín.

Así, el control de la prensa implicaba también a las publicaciones infantiles, ya que se había tenido en cuenta a este tipo de lector para prohibir toda lectura que «siembre ideas perniciosas entre los intelectualmente débiles». ${ }^{20}$

Mediante órdenes ministeriales de 1938 y 1939 se estableció que la publicación de cualquier material impreso sería evaluado por la Sección de Censura, que podía denegar la publicación de obras por motivos doctrinales o, alegando escasez de papel, podía obstaculizar la publicación de otras obras preferentes.$^{21}$ Esta legislación fue especialmente severa para la literatura infantil y juvenil, ya que «condicionó, en cada etapa, la creación, edición, difusión y venta de libros y publicaciones destinadas a la infancia y a la juventud», ${ }^{22}$ a lo que se unió en 1942 la creación del Gabinete de lectura de Santa Teresa de Jesús, cuya valoración moral de las obras serviría a bibliotecas públicas y centros de enseñanza para elegir las lecturas infantiles y juveniles.

La censura alcanzaría su punto álgido en este ámbito en 1952, con el primer órgano autónomo de censura para la literatura infantil y juvenil, la Junta Asesora de Prensa Infantil, ${ }^{23}$ dependiente del Ministerio de Información y Turismo, creado en 1951. Su objetivo era informar sobre la orientación y el contenido de las publicaciones periódicas y no periódicas para niños, remitiendo sus informes al ministerio para denegar o autorizar su edición. Este ministerio llevaría a cabo nuevos reglamentos para la publicación de revistas y folletos, entre estos últimos los cuadernos de aventuras, con unas normas de censura específicas emanadas de la Junta Asesora de la Prensa Infantil, que prescribían lo que había de considerarse a la hora de redactar e ilustrar obras para niños o adolescentes en referencia a cinco bloques: la religión, la moral, el punto de vista psicológico y educativo, los aspectos patrióticos y los

19 Martín, A. «La historieta española de 1900 a 1951», en Arbor, n. extraordinario (septiembre 2011), pp. 97-98.

20 Pascua Febles, I. La literatura traducida y censurada para niños y jóvenes en la época franquista: Guillermo Brown. Las Palmas de Gran Canaria, Universidad de Las Palmas de Gran Canaria, 2011, p. 50.

${ }^{21}$ Ibid., p. 51.

22 Cendán Pazos, F. Medio siglo de libros infantiles y juveniles en España (1935-1985). Madrid, Ediciones Pirámide, 1986, pp. 47-56.

${ }^{23}$ Ministerio de Información y Turismo. «Orden de 21 de enero de 1952 por la que se crea la Junta Asesora de Prensa Infantil», en Boletín Oficial del Estado, n. ${ }^{\circ} 32$ (1952), p. 475. Disponible en http://www.boe. es/datos/pdfs/BOE/1952/032/A00475-00475.pdf. 
aspectos literarios y artísticos. ${ }^{24}$ En esa normativa se exponía un listado exhaustivo de lo que no debía aparecer en estas publicaciones, temas como, por ejemplo: «los cuentos de crímenes, suicidios y todos aquellos en que aparezcan entes repulsivos que puedan perjudicar el sistema nervioso de los niños», «los cuentos en los que se invoque al diablo para obtener algún éxito», «cuentos en que quede malparada la autoridad de padres, maestros, sacerdotes y en general de todas las personas mayores», «los que alaban los malos tratos», «el realismo excesivo o impropio de la relación entre los sexos, tanto si se trata de personajes humanos como de animales», «historietas que pongan en ridículo la vida familiar, como las que señalan engaños matrimoniales, la mujer que hace trabajar al marido en menesteres caseros mientras ella descansa», etc. Además, se haría hincapié en que no se tolerarían "láminas o descripciones que puedan excitar la sensualidad», «efusiones o deslices, o argumentos en que entre el adulterio», «las descripciones que puedan suscitar una curiosidad malsana en torno a los misterios de la generación», así como la exaltación del crimen, el suicidio, la eutanasia, el alcoholismo o la pereza. Por otra parte, en cuanto a lo religioso se debería «separar siempre ángeles y hadas, porque no son armónicos y crean confusión en las mentes infantiles», así como «huir del naturalismo de fondo panteísta».

En este contexto se desarrollaría la publicación de los cuadernos de aventuras Roberto Alcázar y Pedrín, especialmente en sus inicios, «un tiempo de intensa exaltación nacionalista en España, de una fuerte represión política que impregnará inevitablemente cualquier tipo de creación intelectual, con independencia de sus características artísticas y de su calidad». ${ }^{25}$

\section{Los personajes}

El protagonista de esta serie de cuadernos de aventuras, Roberto Alcázar - Roberto Alcázar, el intrépido aventurero español ${ }^{26}$ es un periodista-detective que recorre el mundo persiguiendo sin tregua a los malhechores.

Su físico, de manera esquemática, sería el de un «hombre formal o de buena familia» procede de familia profundamente patriótica y aristocrática, heredero directo de la fortuna de un tío suyo y de sus abuelos, latifundistas en Sudamérica (El monte del diablo, episodio n. $\left.{ }^{\circ} 13,1942\right)$ - Tiene aspecto juvenil; es ágil, inteligente y físicamente fuerte, y su apariencia está de acuerdo a las convenciones estéticas de la época para su clase social: siempre trajeado, con corbata, pelo peinado hacia atrás y engominado. La fisionomía del personaje, en muchas de las historietas acusaría, como se señaló anteriormente, una notable semejanza

${ }^{24}$ Cendán Pazos, F. Op. cit., pp. 55-59.

25 Gual Boronat, Ó. (2013), op. cit., p. 67.

${ }_{26}$ Este fue el título inicial de las historietas hasta el n. ${ }^{\circ}$ 93, en el año 1943, antes de pasar a llamarse Roberto Alcázar y Pedrín. Este cambio puede deberse al "poco definido y frívolo» apelativo de aventurero para el protagonista en una época de exaltación patriótica. Porcel, A. (coord.) «Roberto Alcázar, símbolo de una época», en Historia del tebeo valenciano. Valencia, Editorial Prensa Valenciana, 1992, p. 63. 
con la de José Antonio Primo de Rivera, fundador de Falange Española: el corte de pelo, el peinado, el perfil y «su apostura de líder» ${ }^{27}$ (FIG. 2).

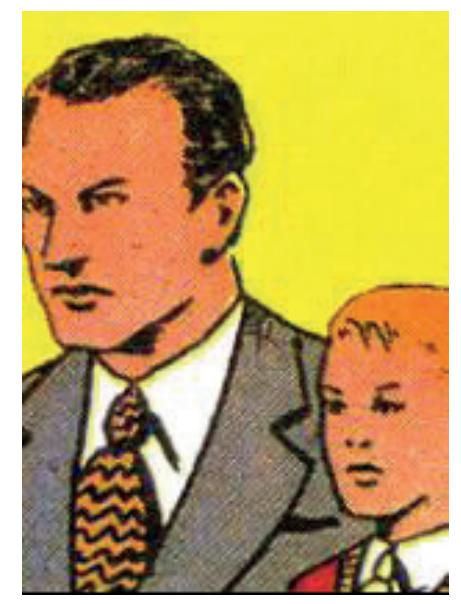

FIG. 2. Fragmento de portada de La banda del trébol, episodio n. ${ }^{\circ} 32$ (1942).

En cuanto al apellido, Alcázar, tiene connotaciones de vinculación al sistema en referencia al episodio de la defensa del Alcázar de Toledo en la Guerra Civil, aunque tanto el guionista Juan Puerto como el dibujante Eduardo Vañó siempre negaron esta relación..$^{28}$ En cualquier caso, el planteamiento del personaje tendría un buen encaje en la sociedad de posguerra además de las características adecuadas de cara a la censura.

Roberto Alcázar es un español orgulloso de serlo -El hijo del emir, episodio n. ${ }^{\circ}$ 23, 1942 (FIG. 3)-. Esto se manifiesta también de manera subliminal cuando se refiere con satisfacción al pasado imperial de su país: «Son los Andes. Por estas montañas pasaron hacia el Pacífico, con mil fatigas y riesgos, los descubridores españoles» (Los tiburones del Pacífico, episodio n. $\left.{ }^{\circ} 7,1941\right)$. Presume allá donde va de «intrépido aventurero hispano» —especialmente en la primera etapa de la revista hasta 1943-; por ejemplo, en las selvas de Centroamérica (El tesoro de los Tobas, episodio n. ${ }^{\circ} 4,1941$ ) o ante los legionarios franceses en el Sahara (El espia del Aggar, episodio n. $\left.{ }^{\circ} 16,1942\right)$.

Su carácter es formal, serio y convencional, no expresa emociones, no tiene novia ni se relaciona con ninguna mujer. ${ }^{29}$ En cuanto a su lucha contra el mal, su único recurso para so-

${ }^{27}$ Rey, J. «Cómic, cultura y propaganda: Los tebeos que yo leí», en Actas de las primeras Jornadas sobre cómic, comunicación y cultura: El cómic en el nuevo milenio. Sevilla, Universidad de Sevilla, 2001, pp. 25-36.

28 Porcel, A. (1992), op. cit., p.63.

${ }^{29}$ Esta cuestión podría relacionarse con el interés de evitar problemas con la censura, pero por el contrario ha dado pábulo a que se haya relacionado con una homosexualidad encubierta del personaje, por estrecha relación con su sempiterno acompañante, el adolescente Pedrín: «una sublimación , por medio de la aventura compartida - y las torturas a dúo- de la tipificación homosexual activo-pasiva». Morx, T. Historia social del cómic. Barcelona, Bruguera, 2007, p. 114. 


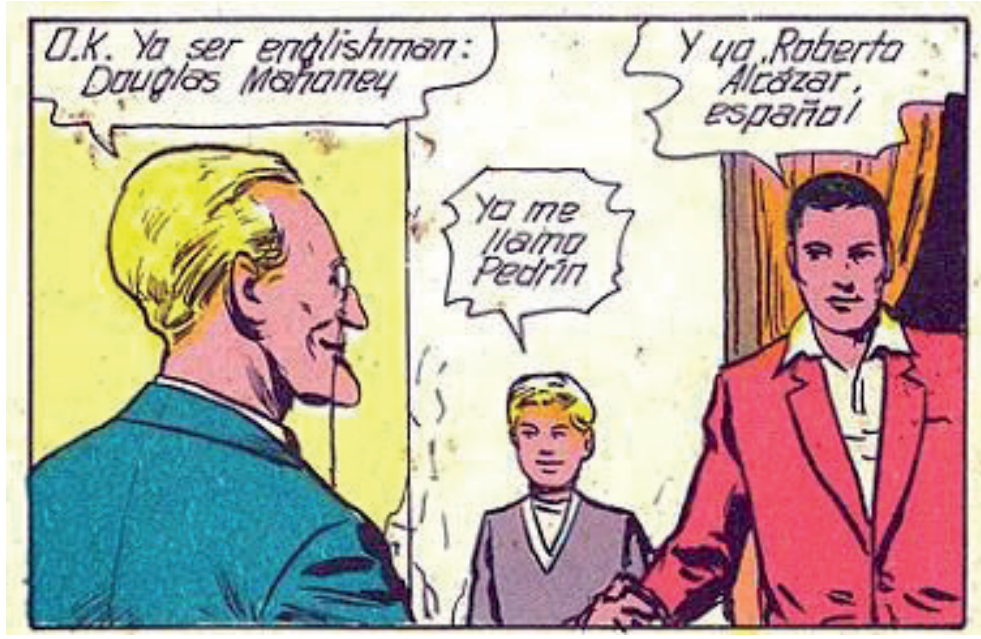

FIG. 3. Viñeta de El hijo del emir, episodio n. ${ }^{\circ} 23$ (1942).

lucionar los conflictos es la violencia, en muchos casos extrema, propio de una época donde esto no es repudiado si es en nombre de una buena causa.

Roberto Alcázar se constituye en tutor y educador de su ayudante, Pedrín, quien representa gran parte de los valores que la escuela franquista propugna para su juventud: respeto al orden y a la autoridad, caballerosidad, valentía, corazón cristiano y generoso, aunque sin los resultados deseados, ya que este se guiará por instintos y principios básicos, mostrándose como un joven irrespetuoso, maleducado y extremadamente violento. ${ }^{30}$

Pedrín sería así el contrapunto de Roberto Alcázar. Se trata de un joven del pueblo, descarado e incluso simpático, pero que presenta rasgos de tipo sádico a la hora de enfrentarse a los delincuentes. Disfruta golpeando y matando, como cuando en uno de los episodios ametralla con gusto a varios negros, diciendo: «Os gustan las peladillas de Alcoy? Pues id tomando que son gratis» (Jumbo el megalómano, episodio n. ${ }^{\circ}$ 213, 1951). Además, no duda en aplicar torturas a los delincuentes (El prisionero de Norfold, episodio n. ${ }^{\circ} 96,1947$ ), como, por ejemplo, mediante corrientes eléctricas, en presencia de la policía, con un texto de apoyo que dice: «Pedrín conecta un cable a las esposas del bandido, el cual se estremece y contorsiona bajo una descarga eléctrica, no mortal pero continua», mientras Roberto interroga: «Hablarás ahora o continuamos la función?»; y Pedrín, orgulloso del resultado de su invento, apostilla: « $i$ Ya sabía yo que cantaría mejor que Jorge Negrete!».

Otros rasgos destacables del personaje de Pedrín son su misoginia y machismo (FIG. 4 y FIG. 5). Cuando trata a mujeres «villanas» las desprecia con superioridad — «Tendremos que darle una azotaina a esta muñeca» (Viaje fantástico, episodio n. ${ }^{\circ} 171,1950$ )—. También las denigra y desprecia como enemigas — «Si no llegas a ser mujer, el primer puñetazo hubiera sido para tì (La derrota del Papá Tigre, episodio n. $\left.{ }^{\circ} 169,1950\right)$ - Si las mujeres están

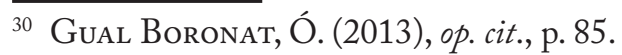


de su lado, han de comportarse obligatoriamente de un modo determinado - «No creo muy natural que una mujer se meta en un bar sola» (El misterio del expreso azul, episodio n. ${ }^{\circ}$, 1941) o «las mujeres que se atreven a viajar solas suelen ser peligrosas» (La gruta del infierno, episodio n. ${ }^{\circ} 452,1960$ ) - además de tratarlas con condescendencia machista: «Hasta pronto hermosas doncellas» (El lobato, episodio n. ${ }^{\circ} 130,1948$ ), o «hay que ser galantes con las damas» —dice Roberto Alcázar-, a lo que Pedrín contesta: «sobre todo cuando están tan imponentes como ésta» (La gruta del infierno, episodio n. ${ }^{\circ} 452,1960$ ).

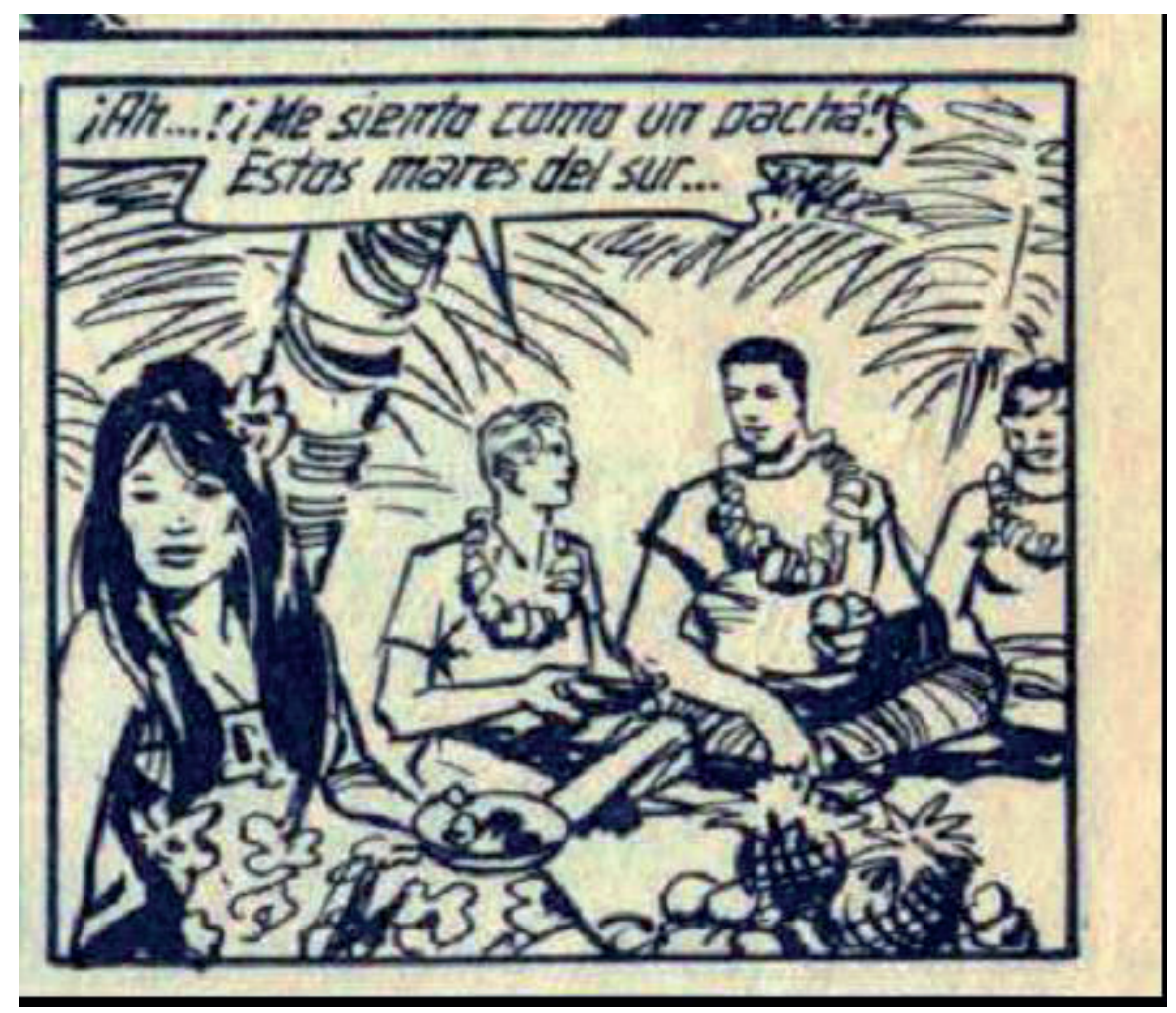

FIG. 4. Viñeta de Los contrabandistas de Hawaii, episodio n. ${ }^{\circ} 259$ (1953).

Básicamente, los personajes de esta serie de historietas se reducen a los dos protagonistas mencionados; no obstante, aparece una serie de tipos intercambiables, generalmente de clase alta, como monarcas, banqueros, comisarios de policía o científicos, que requieren los servicios de los «héroes» para luchar contra los «malos», que a partir del n. ${ }^{0} 94-\mathrm{y}$ durante veintisiete capítulos - se encarnan en un solo personaje llamado Svintus, el «hombre diabólico», que ayudado por Graham, un científico desalmado, tiene como único interés sojuzgar al mundo.

\section{La acción}

Desde el punto de vista espacio-temporal, como se indicó, la acción transcurre siempre en un marco intemporal que permite que las distancias no representen ningún obstáculo, 


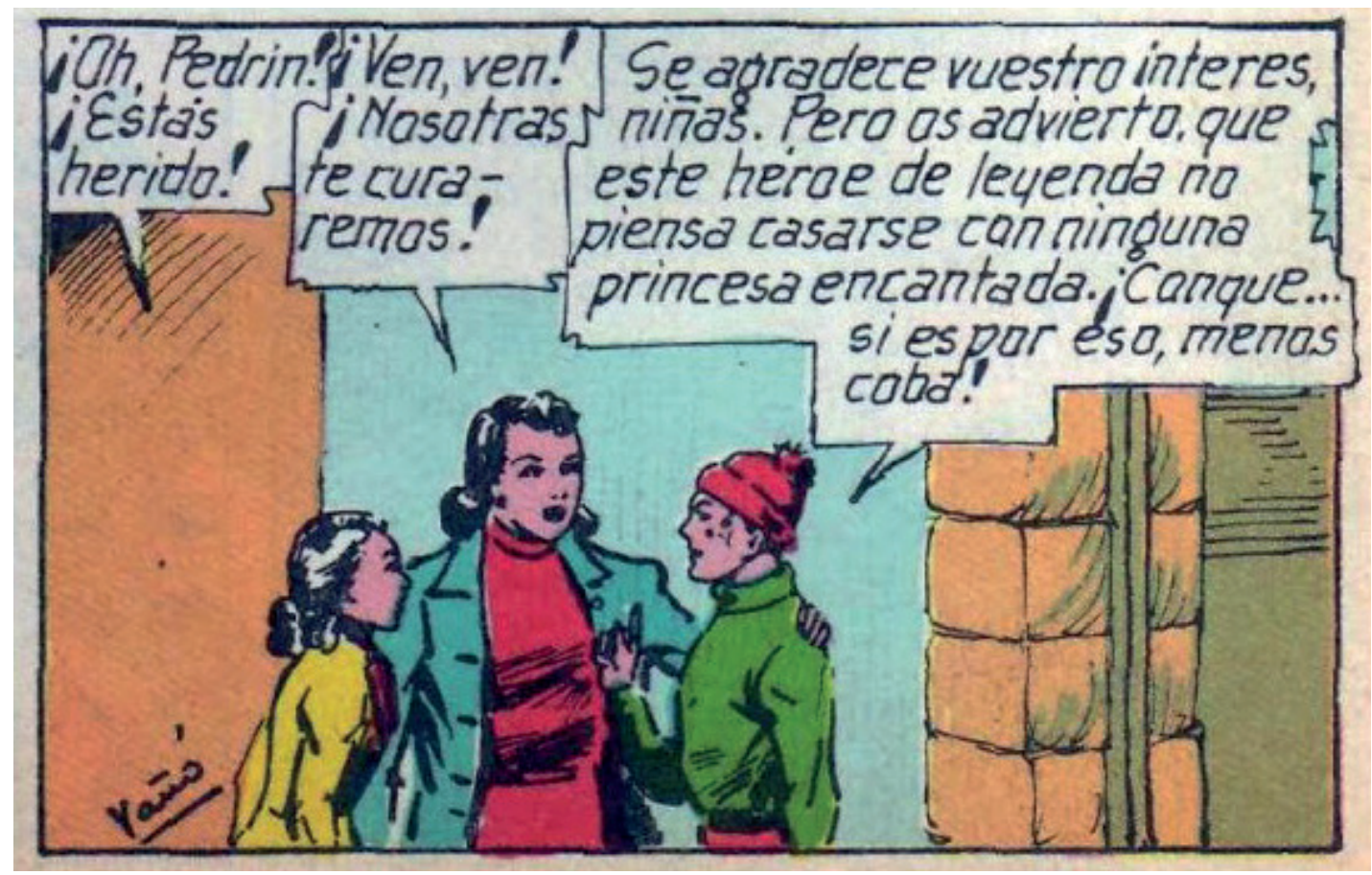

FIG. 5. Viñeta final de El héroe de la profecía, episodio n. ${ }^{\circ} 153$ (1949).

pasando de las costas del Índico al Polo Norte o al Sahara sin ningún problema, propiciándose un gran número de aventuras de ambiente «exótico». En ellas, se manifiesta claramente una visión de tipo colonial (FIG. 6), con autoridades de raza blanca e indígenas a los que se otorgan los papeles de contrapunto cómico, si el indígena está del lado de los buenos - los blancos y las autoridades_- o del «traidor» si pertenece al bando de los malhechores. El exotismo de la aventura se recrea a base de tópicos: en China, con mandarines, torturas... Todo del tipo Fu Manchú. ${ }^{31}$ En África, los negros aparecen como mentalmente inferiores y ataviados con taparrabos; los árabes se muestran traicioneros; y en la India, todo son sectas secretas con adeptos fanáticos y dioses extraños.

Se trataría de una visión etnocéntrica del mundo, donde Occidente se constituye como el centro y todo lo demás pasa a ser periferia. Se ridiculiza a todas las razas excepto a la aria, que con sus gobernantes pone freno a las bárbaras costumbres de las demás. Así, por ejemplo, en El tesoro de los pigmeos (episodio n. ${ }^{\circ} 15,1942$ ) Pedrín pregunta a Roberto Alcázar: «Cúando vamos a encontrar a esos negros enanos?», y Roberto responde: «Son mala gente, Pedrín». En Rebelión en el trópico (episodio n. ${ }^{\circ} 25,1942$ ), un jefe de tribu es engañado con facilidad por la pareja de héroes, que obtienen un territorio a cambio de licores y tabaco. La secuencia finaliza con «mi isla es vuestra, hombres blancos», en el bocadillo del jefe indígena. Respecto a los chinos, son rastreros y siempre atacan por la espalda. En El arca de plata

\footnotetext{
${ }^{31}$ El villano chino que odia a la civilización occidental y a la raza blanca; personaje de novela creado en 1913 por el escritor británico Sax Rohmer.
} 
(episodio n. ${ }^{0} 14,1942$ ), Roberto Alcázar descubre la huella de un enemigo bajo su ventana, y rápidamente detecta la raza del espía por el tamaño de la huella: «De todos es sabido que los chinos calzan números pequeños».

A la vista de estas historietas, la visión del mundo reflejado parece conformarse a partir de influencias del folletín de finales del xix y principios del xx (Verne, Salgari, etc.), junto a la influencia de películas americanas y de la propia ignorancia de los autores, que como muchos otros españoles nunca habían traspasado una frontera.

Como se indicó, la acción nunca transcurre en España, porque «en España no se cometían delitos», nada malo ocurría ya que el absoluto control de la guardia civil o la policía hacía innecesaria cualquier acción salvadora de un héroe como Roberto Alcázar;32 además, para ello ya estaba el «caudillo». Por otra parte, se hacía patente la supremacía de Occidente inculcada por la escuela franquista. Todo ello podría ser en parte consecuencia de una autocensura que Vañó y sus guionistas se impusieron: «Precisamente algo que queríamos era huir de los temas políticos, porque esos temas no podían traer más que problemas con el régimen de entonces». ${ }^{33}$

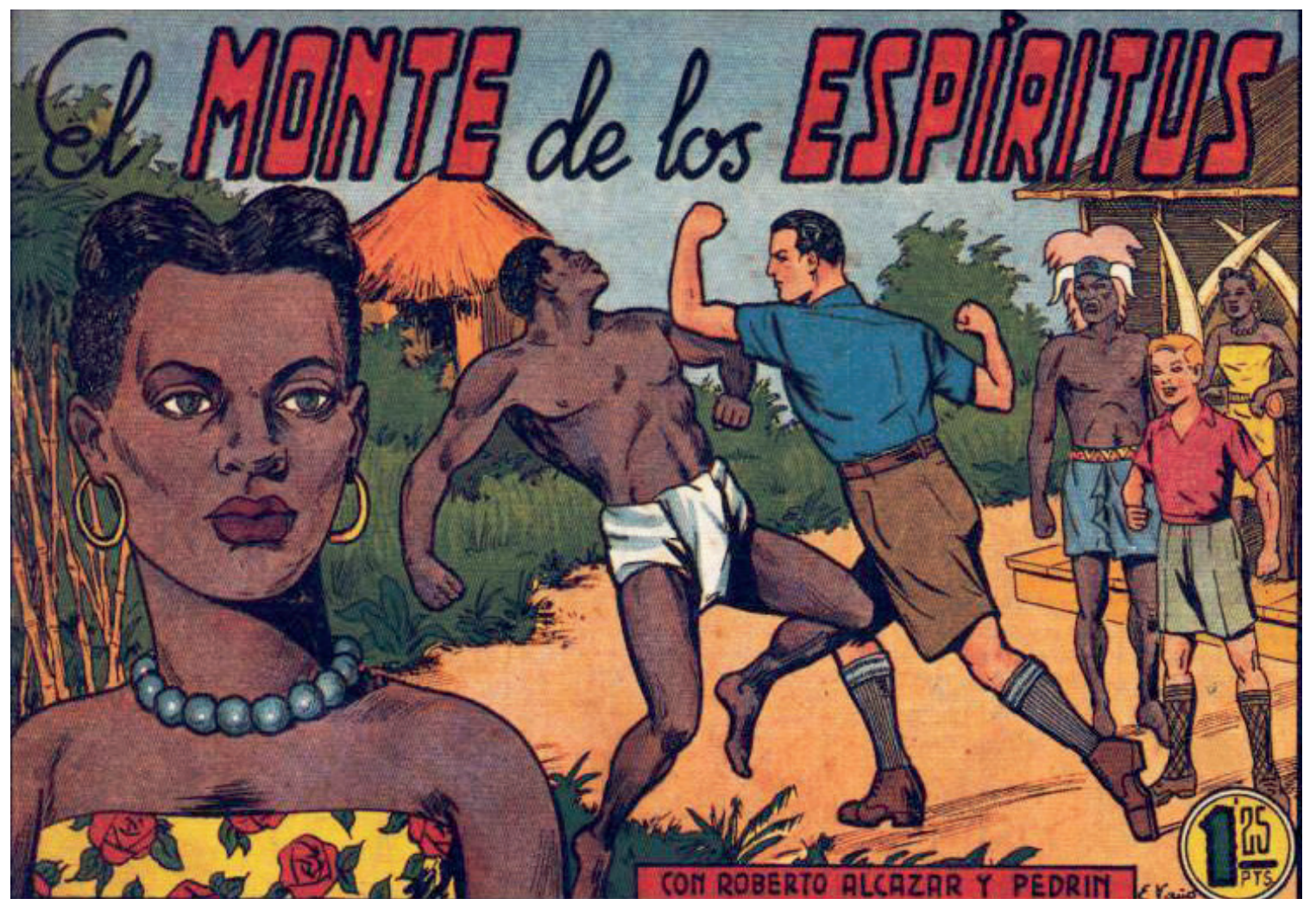

FIG. 6. Portada de El Monte de los espiritus, episodio n. ${ }^{\circ} 319$ (1955).

32 Tadeo J. F. «Roberto Alcázar y Pedrín», en Krazy cómics, n.o 8, 1990, pp. 25-26.

${ }^{33}$ Declaraciones de Eduardo Vañó recogidas en Porcel, A. (1992), op. cit., p. 80. 


\section{Los contenidos}

El esquema de desarrollo de las aventuras es invariable: alguien acude pidiendo ayuda a los héroes, estos inician la investigación y el resto de la historieta es una continua secuencia de persecuciones, insultos y golpes a los malvados de turno, que acaban en la cárcel o muertos.

Se aprecia una concepción de la ley y el orden represiva y vengativa, que considera la muerte del delincuente como algo perfectamente aceptable. ${ }^{34}$ Se encuentran expresiones como «ya me encargaré yo de que no queden impunes tus crímenes» (La entrada al templo, episodio n. ${ }^{\circ}$ 119,1948 ) o «le has ahorrado ese trabajo al verdugo» (El final del trio maldito, episodio n. ${ }^{\circ} 120$, 1948) muy esclarecedoras al respecto. No se encuentra tampoco censurable el uso de la tortura contra el delincuente, ${ }^{35}$ como ilustra gráficamente el momento de la acción, ya mencionado, en que Pedrín aplica la corriente eléctrica a un prisionero.

La violencia, en general, es la pauta de las historietas. Esta cuestión no se censuraba si iba encaminada a una «buena causa»; además, se acompañaba, casi siempre para darle mayor énfasis, de expresiones del tipo de «muere, hijo de perra» o «muere, aborto de Satanás».

En este ambiente, Roberto Alcázar se muestra como un convencido defensor de la propiedad privada. Defiende las joyas y piedras preciosas de empresarios y destacadas personalidades, recupera millones robados en los bancos o entrega herencias más allá de los mares perseguido por delincuentes que se las quieren apropiar. Es un miembro de la élite, se relaciona con personas de ese entorno social. Sin embargo, desprecia a aquellos que ambicionan el dinero o la riqueza si no pertenecen a su clase: lo material no es tan importante, no hay que envidiarlo, existen otros valores más importantes. Todo esto denotaría un claro principio de conservadurismo.

Además, aparece una constante desconfianza hacia lo nuevo, la ciencia o la tecnología, que siempre se muestran como una fuente de peligros y desdichas, recibiendo en general un tratamiento burdo. Esta actitud es muy evidente en la caracterización que se da a los científicos, siempre de apellido extranjero; suelen ser locos malvados o sabios despistados, e invariablemente sus descubrimientos son una amenaza contra la humanidad (FIG. 7). Un tipo de personaje similar es el de los inventores que se presentan repetidamente como resentidos contra el mundo, siendo calificados como «chivos» o «majaretas». Así, en el episodio n. ${ }^{\circ} 327$, Los misteriosos rayos $W$ - $D$, Roberto Alcázar alecciona a Pedrín: «Estos hombres de ciencia, a base de pensar y discurrir, suelen estar un poco chiflados».

Junto a los científicos, arqueólogos y antropólogos, que aparecen en exploraciones en la selva o en indeterminados yacimientos arqueológicos, son invariablemente ridiculizados como

\footnotetext{
${ }_{34}$ En un paralelismo con la situación histórica, donde la aplicación de pena de muerte reinstaurada por Franco en 1938 estaba normalizada.

35 Era una práctica habitual y asumida en la represión franquista de la posguerra. FraguAs, R. «Mapa de la represión en la posguerra», en El País, 2 de mayo de 2010. Disponible en http://elpais.com/diario/2010/05/02/ madrid/1272799462 850215.html.
} 


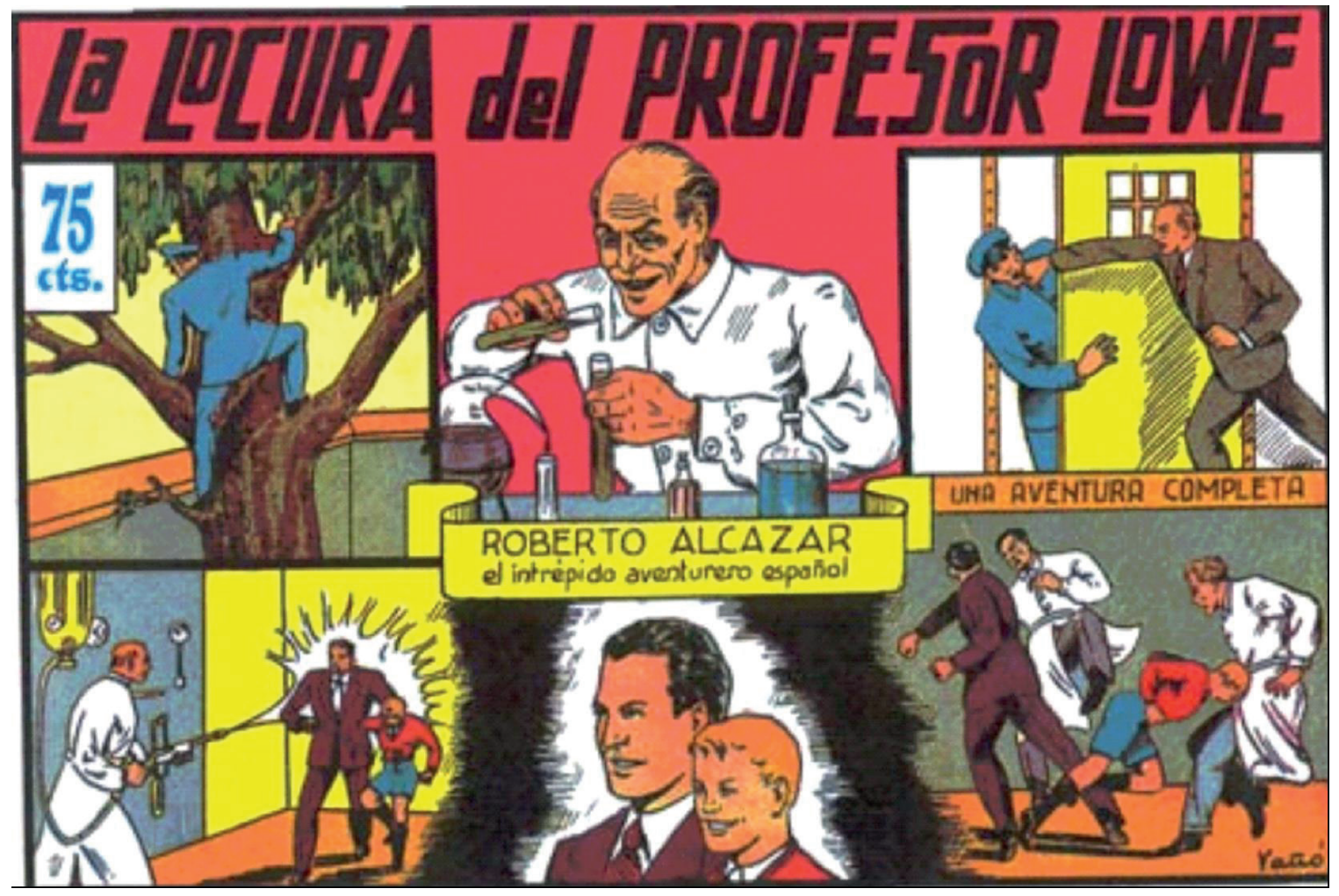

FIG. 7. Portada de La locura del Doctor Lowe, episodio n. ${ }^{\circ} 63$ (1945).

exponentes de actividades incomprensibles e inútiles. Un ejemplo procedente del n.o 368, El pasadizo secreto (1957), es una muestra representativa de esta cuestión: en la exploración de una pirámide, un egiptólogo exclama: «iEstamos a punto de realizar un descubrimiento que cambiará la historia!», a lo que Pedrín replica: «¿Y no sería mejor que descubriera una mina de polos helados?».

Esta imagen de la ciencia, vista como el quehacer de personalidades trastornadas, sería compatible con un verdadero complejo de inferioridad ante otros países - los científicos de las historietas son invariablemente extranjeros- o simplemente con una falta de cultura, consecuencias de una etapa, la posguerra, y más concretamente la autarquía, científicamente eclipsada como lo fueron con anterioridad otros períodos. ${ }^{36}$ Ante esta carencia, las distintas disciplinas científicas son despreciadas de tal manera que se llega, como en este cómic, por parte de Pedrín a exclamar: «iFuera microscopios, tubos de ensayo y demás cacharros!» (El brazalete maldito, episodio n. ${ }^{\circ} 122,1948$, FIG. 8 ).

No cabe duda de que en todo ello habría mucho de ignorancia. Una ignorancia que impregnaba también a la clase popular, consecuencia de un sistema docente deficitario, que se

36 Entre 1808 y 1833, o en torno a 1898. Ayala-Carcedo, F. J. (dir.). Historia de la tecnología en España. Barcelona, Valatenea, 2001, p. 732. 


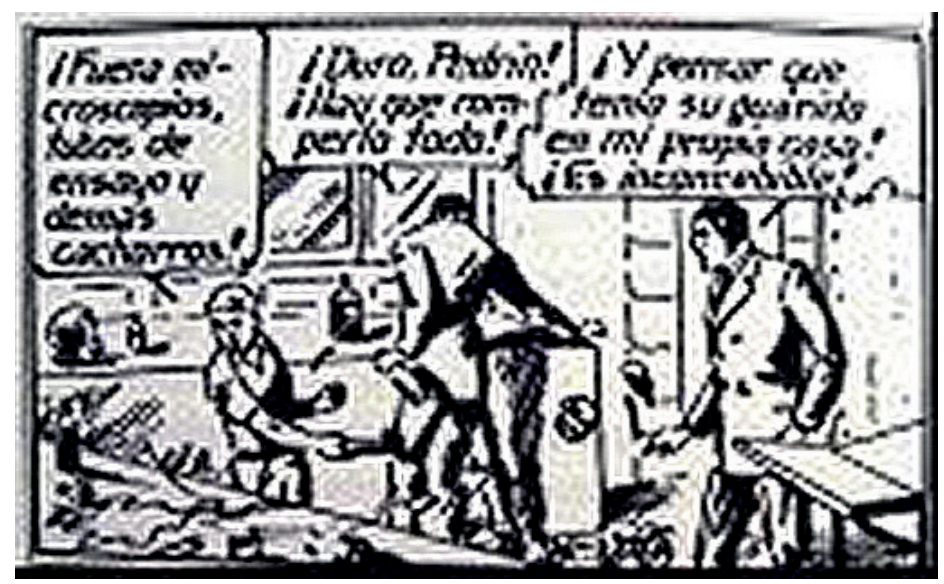

FIG. 8. Viñeta de El brazalete maldito, episodio n. 122 (1948).

refleja claramente en estas historietas. Pedrín sería su paradigma, lo que se muestra en sus diálogos y actitudes de tipo instintivo o de principios muy básicos, mostrándose siempre insolente y agresivo con sus adversarios, «actuando con soluciones violentas y drásticas ante cualquier problema», ${ }^{37}$ siempre armado con una porra, un puño americano o una pistola —con expresiones como « $i$ Que Dios me perdone pero los mato a los dos!» (El misterio del expreso azul, episodio n. $\left.{ }^{\circ} 3,1941\right)$, que no duda en utilizar bajo el beneplácito de su mentor Roberto Alcázar (FIG. 9).

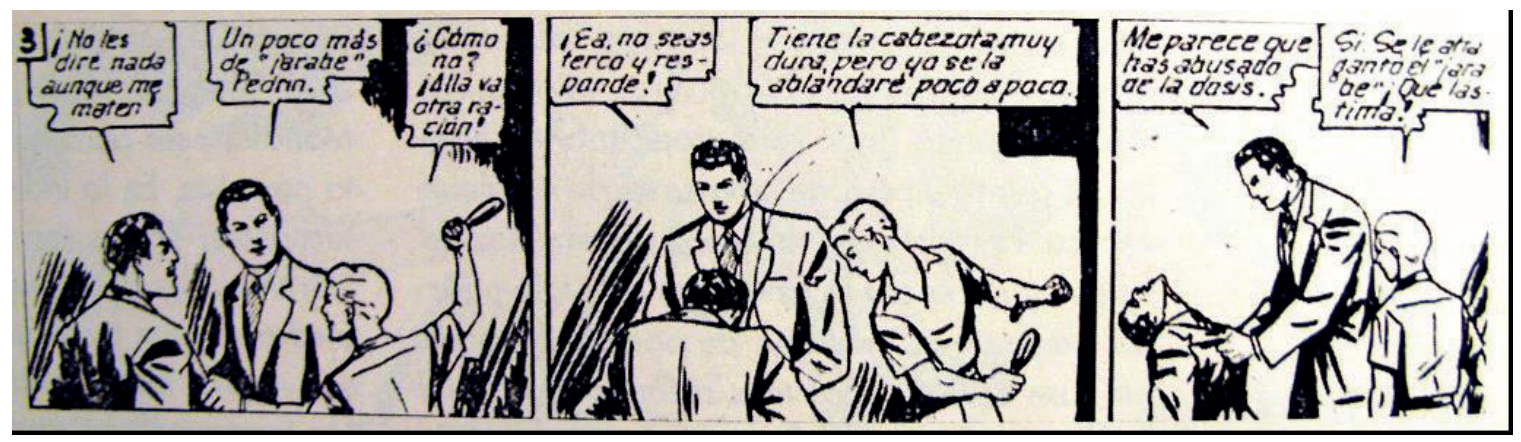

FIG. 9. Viñeta de El fin de un traidor, episodio n. 244 (1953).

\section{A modo de conclusión y una teoría}

La serie de cuadernos de aventuras Roberto Alcázar y Pedrín se presenta como un importante ejemplo de fuente para la investigación de la historia social de España durante el franquismo. Durante el período estudiado — entre los años 1941 y 1959, que se corresponden con la autarquía-, este cómic realizado al margen del aparato propagandístico del régimen, y a pesar de que sus autores pretendían evitar cualquier matiz político para eludir «problemas»

\footnotetext{
37 Vidal, J. De Yellow Kid a Superman. Una visión social del cómic. Barcelona, Milenio, 1999, p. 23.
} 
con la censura, se encuentra totalmente impregnado — ¿inconscientemente?- de valores, sentimientos y actitudes del nuevo orden instaurado.

Independientemente de la polémica en cuanto a si participaba, o no, en la política de adoctrinamiento del régimen, sus contenidos muestran una serie de cuestiones poco discutibles, como es una concepción represiva y vengativa de la ley y el orden, considerando finalmente la muerte de los malhechores como algo perfectamente aceptable. La violencia es la pauta de las historietas, cuestión no censurada, porque se planteaba como encaminada a una «buena causa». En este ambiente, Roberto Alcázar - como arquetipo de «persona de orden» del régimen - se muestra como un convencido defensor de las élites y de la propiedad privada.

No hay clases sociales, no existen conflictos sociales - ni sueldos bajos, hambre, mercado negro o estraperlo - ni laborales. Aparece una sociedad neutra, en los que los privilegiados desprecian la ambición de la clase popular, con lo que parece difundirse un mensaje de tipo conservador, como apunta Óscar Gual:

[El mensaje] de que la riqueza material no es tan importante, que no han de envidiarla, que las cosas se queden como están y nada se mueva. Es el principio del conservadurismo político, el mantenimiento del orden social en el que las masas sigan sometidas, gracias a su carácter pasivo, sin peligro a revoluciones, como la que trajo consigo el triunfo electoral de la República en $1931 .^{38}$

No cabe duda de que estos cómics ponen también de manifiesto la ignorancia que rezumaba la España de la autarquía, así como la ideología franquista que lo impregnaba todo. Una ignorancia que afectaba especialmente a las clases bajas, consecuencia de un sistema docente deficitario, y de una ideología que, supuestamente de manera inconsciente, se transmitía también por ese medio.

El éxito de Roberto Alcázar y Pedrín se podría buscar en el trato simplificador y sintético con que se emplean los arquetipos de los elementos populares utilizados, muy asequibles a un lector de la época no demasiado exigente, que no busca una trama compleja, sino reconocer en cada capítulo un esquema ya asumido.

Además, se podría considerar que el grafismo aportado a la serie por Eduardo Vañó — composición de las portadas, en las que un elemento central es rodeado por otros que definen el significado global de la imagen, colores chillones y fuertemente contrastados, como elementos llamativos- podría ser partícipe de una estética conectada con el kitsch, entendido este como la cultura que se creó en el siglo xx para los campesinos alfabetizados que llegaron a las ciudades con la industrialización; una nueva forma cultural sucedánea que está a medio camino entre lo urbano y el folclore rural, destinada a aquellos que, según Clement Greenberg, «insensibles a los valores de la cultura genuina, estaban hambrientos de distracciones

38 Gual Boronat, Ó. (2013), op. cit., pp.106-107. 
que solo algún tipo de cultura puede proporcionar». ${ }^{39}$ Así, los cuadernos de aventuras, como en el caso de Roberto Alcázar y Pedrín, serían una forma rudimentaria de percepción, donde lo artístico sería una continuidad de la vida real, en contraposición a la vanguardia que se desarrollaba en esos momentos en otros ámbitos y latitudes. ${ }^{40}$

Así, las clases populares poco formadas de la época elegirían siempre el kitsch—por ejemplo, de los cuadernos de aventuras - antes que cualquier otra manifestación artística. Según Greenberg, esta elección se produciría por la existencia un «intervalo social», ya que siempre ha habido, por un lado, «la minoría de los poderosos» - y, por tanto, de los cultos-, y por otro, «la gran masa de los pobres y explotados y, por tanto, de los ignorantes». La cultura formal pertenecería siempre a los primeros, y los segundos tendrían siempre que contentarse con una cultura popular rudimentaria, o con el kitsch. ${ }^{41}$

Esta realidad establecería una relación entre el fascismo y el kitsch, conclusión que, a la larga, se ha revelado como la gran aportación de Greenberg al conectar lo que sucedía en el arte -en este caso, Roberto Alcázar y Pedrín — con los acontecimientos políticos del momento. ${ }^{42}$ De este modo, Greenberg alertaría - a partir de lo que ocurría en la Unión Soviética y en la Alemania nazi- que «allí donde un régimen político establece una política cultural oficial, lo hace en bien de la demagogia». ${ }^{43}$ Por eso, desde su punto de vista, el estímulo del kitsch «no es sino otra manera barata por la cual los regímenes totalitarios buscan congraciarse con sus súbditos», ${ }^{44}$ una forma de halagar a las masas haciendo que la cultura descienda hasta su nivel.

Este podría ser el caso de Roberto Alcázar y Pedrín, lo que abriría las puertas a un estudio más profundo en su relación con el kitsch de acuerdo a las teorías estéticas de Adorno, Benjamin o Marcuse.

39 Greenberg, C. Arte y cultura: Ensayos críticos. Barcelona, Paidós, 2002, p. 16.

${ }^{40}$ La vanguardia delimitaría el arte y la vida, marcando las convenciones del lenguaje artístico, y convirtiendo la comunicación en una compleja red de significados para lo que es necesaria la interpretación.

41 Greenberg, C. Op.cit., p. 23.

42 De Llano, P. «Vanguardia y kitsch en el universo del totalitarismo», en Anuario del Departamento de Historia y Teoría del Arte, Universidad Autónoma de Madrid, n. 25 (2013), p. 80. Disponible en https://repositorio.uam. es/bitstream/handle/10486/662768/ADHTA 25 5.pdf? sequence=1.

${ }^{43}$ Greenberg, C. Op. cit., p. 25.

44 Idem. 


\section{Bibliografía}

Ayala-Carcedo, F. J. (dir.). Historia de la tecnología en España. Barcelona, Valatenea, 2001.

Cendán Pazos, F. Medio siglo de libros infantiles y juveniles en España (1935-1985). Madrid, Ediciones Pirámide, 1986.

De Llano, P. «Vanguardia y kitsch en el universo del totalitarismo», en Anuario del Departamento de Historia y Teoría del Arte, Universidad Autónoma de Madrid, n. ${ }^{\circ} 25$ (2013), pp. 75-91. Disponible en https://repositorio.uam.es/bitstream/handle/10486/662768/ADHTA 25 5.pdf?sequence=1

Fraguas, R. «Mapa de la represión en la posguerra», en El País, 2 de mayo de 2010. Disponible en http://elpais.com/diario/2010/05/02/madrid/1272799462 850215.html

Greenderg, C. Arte y cultura: Ensayos críticos. Barcelona, Paidós, 2002.

Gual Boronat, Ó. Bocadillos de autarquía. La historieta del primer franquismo. Valencia, Departament d'Historia Contemporània. Universitat de València, 2008.

-Viñetas de posguerra. Los cómics como fuente para el estudio de la bistoria. Valencia, Universitat de València, 2013.

Lara, A. (coord.) Tebeo. Los primeros cien años. Madrid, Anaya, 1996.

Martín, A. «La historieta española de 1900 a 1951», en Arbor, n. ${ }^{\circ}$ extraordinario (septiembre 2011), pp. 97-98.

Ministerio de Información y Turismo. «Orden de 21 de enero de 1952 por la que se crea la Junta Asesora de Prensa Infantil», en Boletin Oficial del Estado, n. 32 (1952), p. 475. Disponible en http://www.boe.es/datos/pdfs/BOE/1952/032/A00475-00475.pdf

Morx, T. Historia social del cómic. Barcelona, Bruguera, 2007.

Molinero, C. La captación de las masas. Politica social y propaganda en el régimen franquista. Madrid, Cátedra 2005.

Otero, L. Flechas y Pelayos. Moral y estilo de los niños franquistas que soñaban imperios. Madrid, Editorial EDAF, 2000.

Pascua Febles, I. La literatura traducida y censurada para niños y jóvenes en la época franquista: Guillermo Brown. Las Palmas de Gran Canaria, Universidad de Las Palmas de Gran Canaria, 2011.

Porcel, A. (coord.) «Roberto Alcázar, símbolo de una época», en Historia del tebeo valenciano. Valencia, Editorial Prensa Valenciana, 1992, pp. 113-150.

- La historia del tebeo valenciano. Onil, Edicions de Ponent, 2002. 
— «La historieta española de 1951 a 1970», en Arbor, n. ${ }^{\circ}$ extraordinario (septiembre 2011), pp. 129-158.

—Superhombres ibéricos. Onil, Edicions de Ponent, 2014.

Ramírez, J. A. «Grupos temáticos del tebeo de aventura en la España de posguerra: Notas para una historia de la iconografía e ideología (y II)», en Cuadernos de Realidades Sociales, n. 9 (1976), pp. 87-150.

— «Estructura e ideología del tebeo de aventuras en la España de la posguerra», en Cuadernos de Realidades Sociales, n. ${ }^{\circ} 13$ (1977), pp. 27-46.

ReY, J. «Cómic, cultura y propaganda: los tebeos que yo leí», en Actas de las primeras Jornadas sobre cómic, comunicación y cultura: El cómic en el nuevo milenio. Sevilla, Universidad de Sevilla, 2001, pp. 25-36.

Tadeo, J. F. «Roberto Alcázar y Pedrín», en Krazy cómics, n. o 8 (1990), pp. 25-26.

Vázquez, J. M. Prensa Infantil y Juvenil: Pasado y presente. Madrid, Comisión de Información y Publicaciones Infantiles y Juveniles. Dirección General de Prensa del Ministerio de Información y Turismo, 1967.

Vidal, J. De Yellow Kid a Superman. Una visión social del cómic. Barcelona, Milenio, 1999.

VV. AA. «El folletín por entregas y el serial», en Anàlisi, n. 9 (1984), pp. 143-166. Disponible en http://www.raco.cat/index.php/Analisi/article/view/41273/88288. 